\title{
Comparative study of dielectric properties of the skin of human and labora- tory animals
}

\author{
$\underline{\text { Andrew K. Martusevich }}^{1}$, A.G. Galka ${ }^{1,2}$, S.Yu. Krasnova ${ }^{1}$, D.V. Yanin ${ }^{1,2}$, A.V. Kostrov ${ }^{1}$ \\ ${ }^{1}$ Privolzhsky Research Medical University, Nizhny Novgorod, Russia, cryst-mart@yandex.ru \\ ${ }^{2}$ Institute of applied Physics, Nizhny Novgorod, Russia
}

Work on the study of electrical conductivity of tissues, including skin, first appeared about 40 years ago [12]. Since that time, the number of publications, despite their interesting results, is relatively small [7$11]$.

The skin, despite the superficial localization, being a difficult object for visualization, for a long time remained only the subject of histological examination [2, 5, 7, 9-12]. Existing methods (for example, optical coherence tomography, IR thermography, etc.) allow to study only the surface and the nearest surface structures of the skin $[2,5,6,10]$.

A more extensive methodological apparatus is available for monitoring skin vessels [5], while the deep structure of the latter is difficult for non-invasive study $[1,2,5]$. In this regard, the work on profiling of the skin by its dielectric properties attracts attention $[1,3,4,6,8]$, but this information is isolated and jerky. This is, in particular, due to the lack of available diagnostic tools for assessing the dielectric characteristics of the skin and other tissues [3, 4].

In this regard, the aim of the study was to study the possibilities of near-field microwave sensing in assessing the structure of human and rat skin.

\section{Material and methods}

The study, which included a single microwave sounding, was performed in 20 practically healthy people and 20 healthy mature male Wistar rats.

Near-field microwave sensing of tissues was performed using a special installation created in the Institute of Applied Physics of the RAS (Nizhny Novgorod), as well as specialized software that interfaces the installation with a PC and allows to calculate the real part of the dielectric permeability [3]. The dielectric characteristics of the skin were evaluated at depths of 2 to $5 \mathrm{~mm}$ using a series of probes.

Measurement in all examined people was performed on the forearm at a single point, and in animals - at one point, localized in the middle part of the back, on a pre-epilated surface.

The obtained data were processed in the program package Statistica 6.1.

\section{Results and discussion}

It was found that the real part of the dielectic permeability of human skin increases monotonously with increasing depth of sounding (Fig. 1), showing a tendency to increase by 1.74 times when comparing the parameter values obtained at depths of 2 and 5 $\mathrm{mm}(\mathrm{p}<0.05)$.

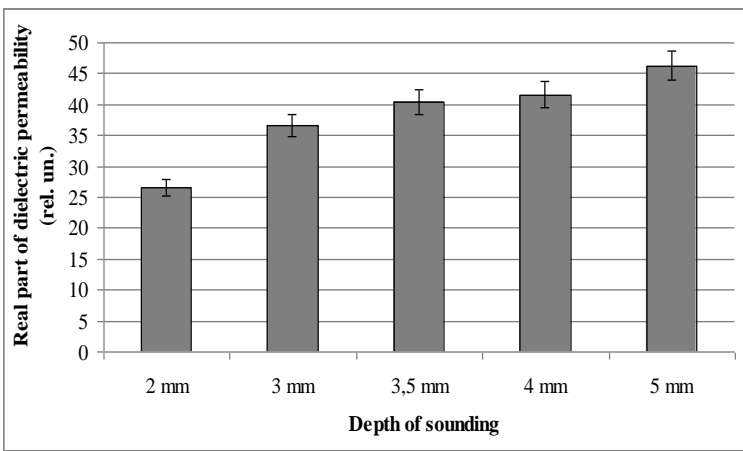

Fig. 1. The profile of dielectric permeability of the skin in healthy people (in rel. un.)

This is due to the fact that the value under consideration is cumulative, and each subsequent value includes the previous as well as the contribution made by tissues located from the previous to the current level of sensing. On the basis of the obtained data, a linear mathematical model of the change in the dielectrical permeability of the skin is constructed, which sufficiently describes its subsurface profile (determination coefficient - 0.94)

The linear regression equation, which allows to predict the value of dielectric permittivity at other sensing depths, is presented in the following form:

$$
y=6,4125 \bullet x+15,844
$$

Analysis of the dielectric properties of rat skin allowed to establish that the permeability of the latter is significantly, almost an order of magnitude lower than in humans, but the nature of the dependence of the considered parameter remains, demonstrating a monotonously increase in the value with a maximum at a depth of $5 \mathrm{~mm}$ (fig. 2).

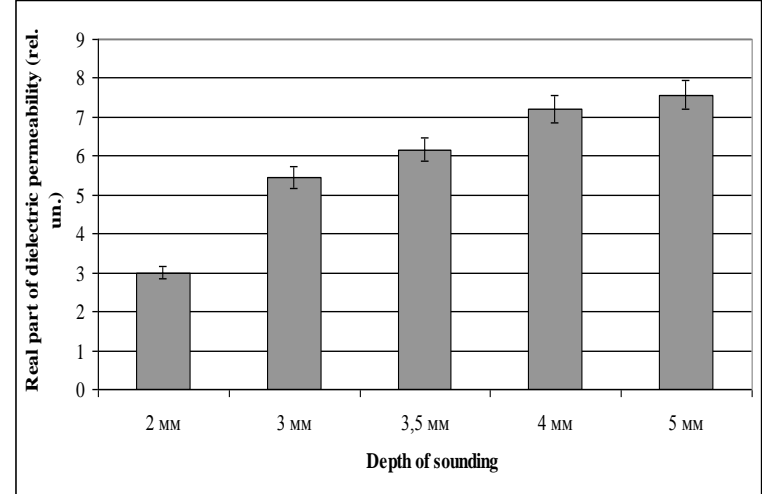

Fig. 2. The profile of dielectric permeability of the skin in healthy rats (in rel. un.) 
At the same time, the level of the studied parameter at the minimum and maximum depths differs by 2.55 times $(\mathrm{p}<0.01)$, which is related to the assessment of deeper structures in rats during microwave profiling by a single date that performs sounding at a depth of $5 \mathrm{~mm}$.

For the microwave profile of the skin of rats, we also formed the linear regression equation, as well as for humans, which fully reflects the experimentally obtained values of the dielectric permittivity (the determination coefficient is 0.91 ). This equation has the following form:

$$
y=1,55 \bullet x+0,455
$$

\section{Conclusion}

The conducted studies allowed to establish a picture of the deep distribution of dielectrical permeability of the skin of healthy people and animals (Wistar rats), which can serve as a physiological microwave pattern for the study of subsurface tissues, including various layers of the skin and the nearest subcutaneous structures. It is shown that the real part of the dielectric permittivity at all the studied depths in humans is much higher than in rats, and monotonically increases with an increase in the sensing depth in the range from 2 to $5 \mathrm{~mm}$ in increments of 0.5 to $1 \mathrm{~mm}$.

The stability of this pattern precedes the possibility of using the method of microwave profiling of the skin in the assessment of its structure in normal and local changes (benign and malignant neoplasms, burns, etc.), and the obtained equations can serve as a guide for the subsequent study of the dielectric characteristics of human cover tissues and mature rats in different experiments.

\section{References}

1. Arsenyev A.V., Volchenko A.N., Likhacheva L.V., Pechersky V.I. The use of the method of HF nearfield sounding in diagnostics of bioobjects // Scientific and technical Gerald of information technologiesm mechanics and optics. 2011. No 2. P. 154-157.

2. Gladkova N.D., Sergeev A.M. PGuidelines on optic coherence tomography. Moscow: Fizmatlit, 2007. $295 \mathrm{p}$.

3. Kostrov A.V., Smirnov A.I., Yanin D.V. et al. Resonanse near-field microwave diagnostics of nonhomogenous mediums. Izvestiya RAS. Ser, Phys. 2005. V. 69, No 12. P. 1716-1720.

4. Reznik A.N., Yurasova N.V. Near-field microwave tomography of biological objects // Zhurnal technicheskoi fiziki. 2004. V. 74, No 4. P. 108-116.

5. Turchin I.V. Methods of optiv biomedical visualization: from subcellular structures to tissues and ograns // Uspechi fizicheskih nauk. 2016. V. 186, No 5. P. $550-567$.

6. Gaikovich K.P. Subsurface near-field scanning tomography // Physical Review Letters. 2007. Vol. 98, N 18. P.183902.

7. Hayashi Y., Miura N., Shinyashiki N., Yagihara $S$. Free water content and monitoring of healing processes of skin burns studied by microwave dielectric spectroscopy in vivo // Phys. Med. Biol. 2005. Vol. 50. N4. P. N8-N14.

8. Raicu V., Kitagawa N., Irimajiri A. A quantitative approach to the dielectric properties of the skin // Physics in Medicine and Biology. 2000. Vol. 45, N2. P. L1-L4.

9. Schertlen R., Pivit F., Wiesbeck W. Wound diagnostics with microwaves // Biomed. Tech. (Berlin). 2002. Vol. 47. Suppl 1, Pt. 2. P. 672-673.

10.Semenov S. Microwave tomography: Review of the progress towards clinical applications // Philos. Trans A Math Phys. Eng. Sci. 2009. Vol. 367, N 1900. P. 3021-3042.

11.Sunaga T., Ikehira H., Furukawa S. et al. Measurement of the electrical properties of human skin and the variation among subjects with certain skin conditions // Phys. Med. Biol. 2002. Vol. 47, N 1. P. N11N15.

12.Tamura T., Tenhunen M., Lahtinen T. et al. Modelling of the dielectric properties of normal and irradiated skin // Phys. Med. Biol. 1994. Vol. 39, N 6. P. 927-936. 